\title{
Neurologic complications of sickle cell disease in Africa
}

\author{
A systematic review and meta-analysis \\ OPEN
}

Jean Jacques Noubiap, MD*

Michel K. Mengnjo, MD

Nicolas Nicastro, MD

Joseph Kamtchum-

Tatuene, MD, FEBN*

Correspondence to

Dr. Kamtchum-Tatuene:

tatuene@liverpool.ac.uk

Editorial, page 1439

Supplemental data at Neurology.org

\section{ABSTRACT}

Objective: To summarize prevalence data on the neurologic complications of sickle cell disease (SCD) in Africa.

Methods: We searched EMBASE, PubMed, and African Index Medicus to identify all relevant articles published from inception to May 31, 2016. Each study was reviewed for methodologic quality. A random-effects model was used to estimate the prevalence of neurologic complications of SCD across studies.

Results: Thirty-one studies were included. Methodologic quality was high or moderate in $90 \%$ of studies. Stroke, conditional and abnormal cerebral blood flow, seizures, and headache were the complications most frequently reported, with overall prevalence rates of $4.2 \%, 10.6 \%, 6.1 \%$, $4.4 \%$, and $18.9 \%$, respectively. Some complications, like silent brain infarcts, peripheral neuropathies, neurocognitive deficits, or moyamoya disease, have been rarely or not studied at all in the African setting. Incidence data were scarce and of poor quality.

Conclusions: The burden of neurologic complications of SCD is important in Africa and most likely underestimated. A better evaluation of this burden requires larger prospective studies using standard up-to-date screening methods. Accessibility to diagnostic tools such as neuroimaging, transcranial Doppler, EEG, and neuropsychological evaluation, as well as to preventive and therapeutic interventions and trained health care providers, should be improved in routine clinical practice.

Neurology ${ }^{\circledast}$ 2017;89:1516-1524

\section{GLOSSARY}

CBF = cerebral blood flow; CTT = chronic transfusion therapy; $\mathbf{S C D}=$ sickle cell disease; TAMM = time-averaged mean of the maximum; TCD = transcranial Doppler

Sickle cell disease (SCD) affects $83 \%$ of the 330,000 babies born each year with a major hemoglobinopathy worldwide. Of the 20-25 million people living with SCD worldwide, 12-15 million live in Africa. ${ }^{1,2}$

By decreasing order of frequency, neurologic complications of SCD include silent brain infarcts $(39 \%$ by age 18$)$, acute and chronic headache (36\% in children), neurocognitive impairment $(25 \%)$, seizures $(7 \%-10 \%)$, ischemic stroke (1\% in children with effective screening and prophylaxis, but nearly $11 \%$ in children without screening), and hemorrhagic stroke (3\% in children and $10 \%$ in adults). ${ }^{3-5}$ These data are mainly derived from populations residing outside Africa and little has been done to provide a more accurate evaluation of the burden of SCD and its complications in Africa, which has the highest prevalence of the disease, despite the resolution adopted by the 63rd session of the UN General Assembly recognizing SCD as a major public health concern. ${ }^{6}$

\footnotetext{
*These authors contributed equally to this work.

From the Department of Medicine (J.J.N.), Groote Schuur Hospital and University of Cape Town, South Africa; Department of Medicine and Medical Specialties, Faculty of Medicine and Biomedical Sciences (M.K.M.), University of Yaoundé, Cameroon; Division of Neurorehabilitation, Department of Clinical Neurosciences (N.N.), Geneva University Hospitals, Switzerland; Brain Infections Group, Institute of Infection and Global Health (J.K.-T.), University of Liverpool; and Department of Neurology (J.K.-T.), The Walton Centre for Neurology and Neurosurgery, Liverpool, UK. Go to Neurology.org for full disclosures. Funding information and disclosures deemed relevant by the authors, if any, are provided at the end of the article. The Article Processing Charge was funded by the University of Liverpool through the Wellcome Trust/COAF block grant for Open Access.

This is an open access article distributed under the terms of the Creative Commons Attribution License 4.0 (CC BY), which permits unrestricted use, distribution, and reproduction in any medium, provided the original work is properly cited.
} 


\section{Figure 1 Flowchart summarizing the article selection process}

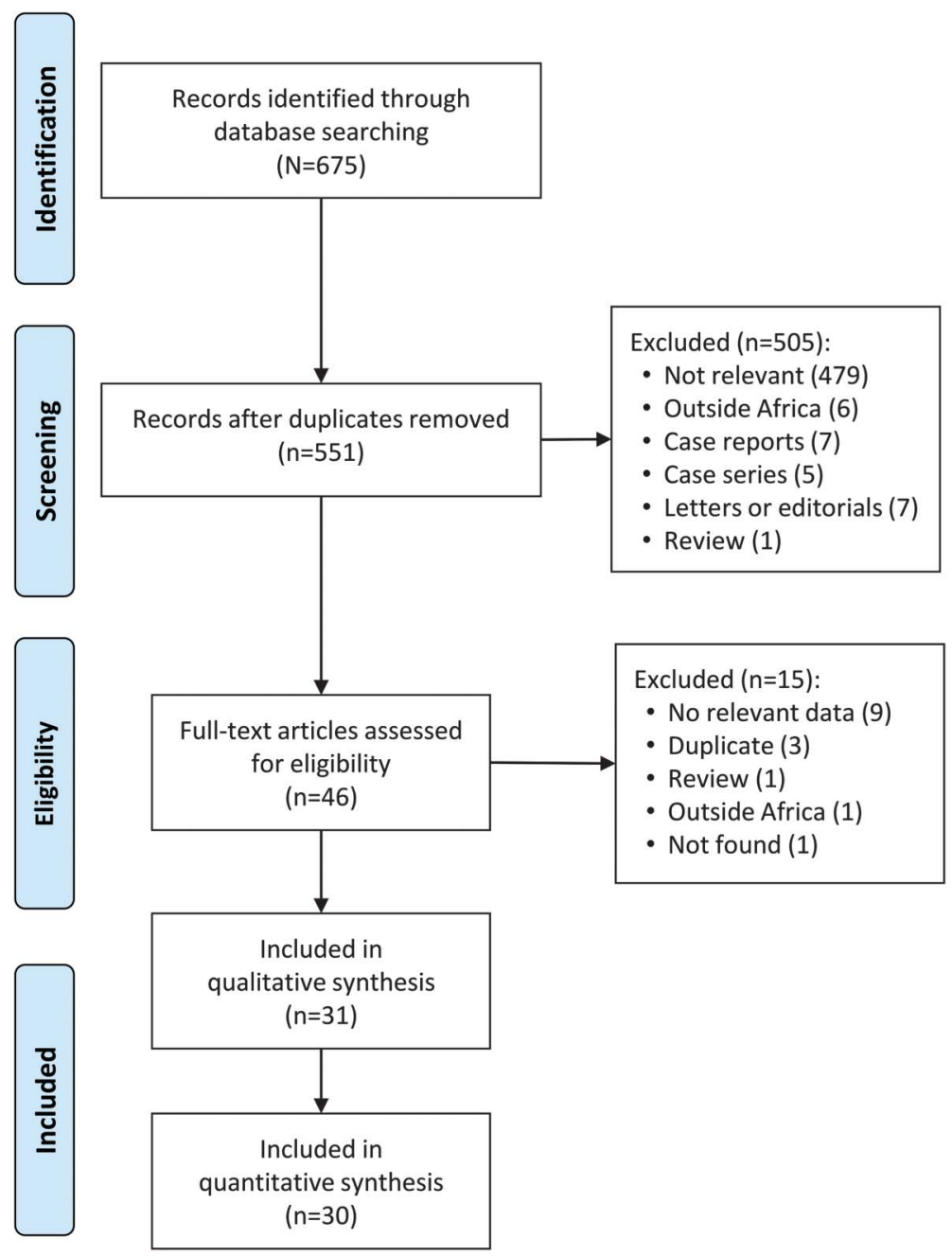

Therefore, we conducted the first systematic review and meta-analysis to summarize prevalence data on the neurologic complications of SCD in Africa and to identify knowledge gaps that may be addressed in future studies.

METHODS The Preferred Reporting Items for Systematic Reviews and Meta-Analyses guidelines served as the template for reporting the review. This review was registered in the PROSPERO international prospective register of systematic reviews (registration number CRD42016039574) and its protocol was published.?

Literature search. We performed a search of PubMed/MEDLINE, EMBASE, and African Index Medicus to identify all relevant articles reporting data on the neurologic complications of SCD in Africa published from inception to May 31, 2016. No language restrictions were applied. Details of the search strategy have been reported previously. ${ }^{7}$

Selection of studies for inclusion in the review. We included all observational studies and clinical trials reporting the prevalence and incidence of the neurologic complications of SCD in an African population. Studies conducted on non-
African populations, small case series ( $<30$ participants), letters, reviews, and editorials were excluded. Details of the study selection process have been reported previously. ${ }^{7}$

Two investigators (J.J.N., J.K.-T.) independently screened the titles and abstracts of the articles identified during the initial literature search, and then the full text of articles found potentially eligible were obtained and further assessed for final inclusion (figure 1). Disagreements were resolved through consensus following a discussion between the 2 assessors. The interrater agreement for the selection of studies was assessed using a nonweighted Cohen kappa. The Cohen kappa statistic is a measure of the true agreement between 2 observers. It indicates the proportion of the possible beyond chance agreement that is attributable to the individual performance of the observers. ${ }^{8-10}$

Appraisal of the risk of bias. Two investigators (J.J.N., J.K.-T.) independently assessed the methodologic quality and the risk of bias for each study by using a 10-point rating system as described previously. ${ }^{7,11}$ Studies were rated as having a low, intermediate, or high risk of bias when they were assigned a score higher than 8 , between 6 and 8 , or lower than 6 , respectively. ${ }^{711}$ Disagreements on the category of bias were resolved through consensus following a discussion between the 2 assessors. The interrater agreement for the score and the category of bias assigned was assessed using a weighted Cohen kappa. A linear weighting system was used in this case. When the decision of the observers is expressed as an ordinal categorical variable with at least 3 possible values, a weighted Cohen kappa statistic is preferred because it accounts for the magnitude of the disagreement. ${ }^{12,13}$

Data extraction and management. For each study, the following information was collected: surname of the first author, year of publication, PubMed accession number (pmid), country and region of Africa where the study was conducted, study setting (urban vs rural, hospital-based vs community-based), study design, duration of follow-up for cohort studies, sample size, mean age and age range, proportion of male participants, diagnostic test for SCD, operational definition, diagnostic method, and prevalence of each complication reported. Data were extracted using a predesigned form (appendix e-1 at Neurology.org). At the end of the extraction process, 2 investigators (J.J.N., J.K.-T.) checked all the data for accuracy. Disagreements were solved through consensus following a discussion between the 2 assessors.

Statistical analyses. The meta-analyses were carried out with the software STATA (version 13; StataCorp, College Station, TX) using the metaprop command. ${ }^{14}$ The heterogeneity between studies was evaluated with the Cochran Q test and quantified using the $I^{2}$ index. ${ }^{15} I^{2}$ values of $25 \%, 50 \%$, and $75 \%$ were interpreted as low, medium, and high heterogeneity, respectively. The confidence intervals for the study-specific prevalence were computed using the score method. ${ }^{14,16}$ Due to the high heterogeneity between studies, pooled prevalence of the various neurologic complications of SCD were computed using a random effect model ${ }^{17}$ after stabilizing the variance with the Freeman-Tukey double arcsine transformation. ${ }^{14,18,19}$ Results of the meta-analyses were presented as forest plots. Sensitivity analyses were performed to evaluate the influence of each study or subgroup of studies on overall prevalence estimates and to identify potential sources of heterogeneity. The subgroups were predefined in the protocol. ${ }^{7}$ Assessment of the small-study effects was carried out by combining visual inspection of funnel plots with the Egger test. ${ }^{20}$ Statistical significance was defined as $p<0.05$. 
RESULTS Study selection. The initial literature search retrieved 675 articles, of which 46 were selected for full-text review. Of these, 31 were eligible and included in this systematic review (figure 1). ${ }^{21-51}$ There was $93.8 \%$ agreement between investigators for study inclusion $(\kappa=0.55)$.

Characteristics of included studies. All the studies included were hospital-based and conducted in 14 countries distributed across 4 of the 5 WHO subregions of Africa with reports published between 1977 and 2016 (table e-1). Ninety percent of the studies were classified as having a low or moderate risk of bias (table e-1). There was 93.6\% agreement between investigators for the scoring of methodologic quality and risk of bias $(\kappa=0.75)$.

Pooled prevalence and incidence of the complications most frequently reported. Stroke. The overall prevalence of stroke in SCD was $4.2 \%$ in a pooled sample of 18,977 participants from 23 studies (figure 2). This prevalence was higher in studies with smaller sample size (figure e-1) and the Egger test for small study effects was significant (bias statistic $=0.64, p=$ 0.005 , funnel plot provided as figure e-2). The prevalence of stroke in SCD was also higher in the 11 studies using more reliable diagnostic criteria for stroke (WHO clinical case definition or brain CT or MRI), representing a pooled sample of 4,257 patients with SCD as shown in figure 2. Finally, the prevalence of stroke in SCD was higher in studies published after 2011 (figure e-3). Only one study investigated the incidence rate of stroke in SCD. This was 3 per 100 person-years in a sample of 66 patients aged 37-197 months and followed up over 12 months. ${ }^{21}$

The type of stroke (ischemic vs hemorrhagic) was reported in 4 studies. $^{22-25}$ In one of these studies,

Figure 2 Meta-analysis of the prevalence of stroke in sickle cell disease according to the diagnostic criteria

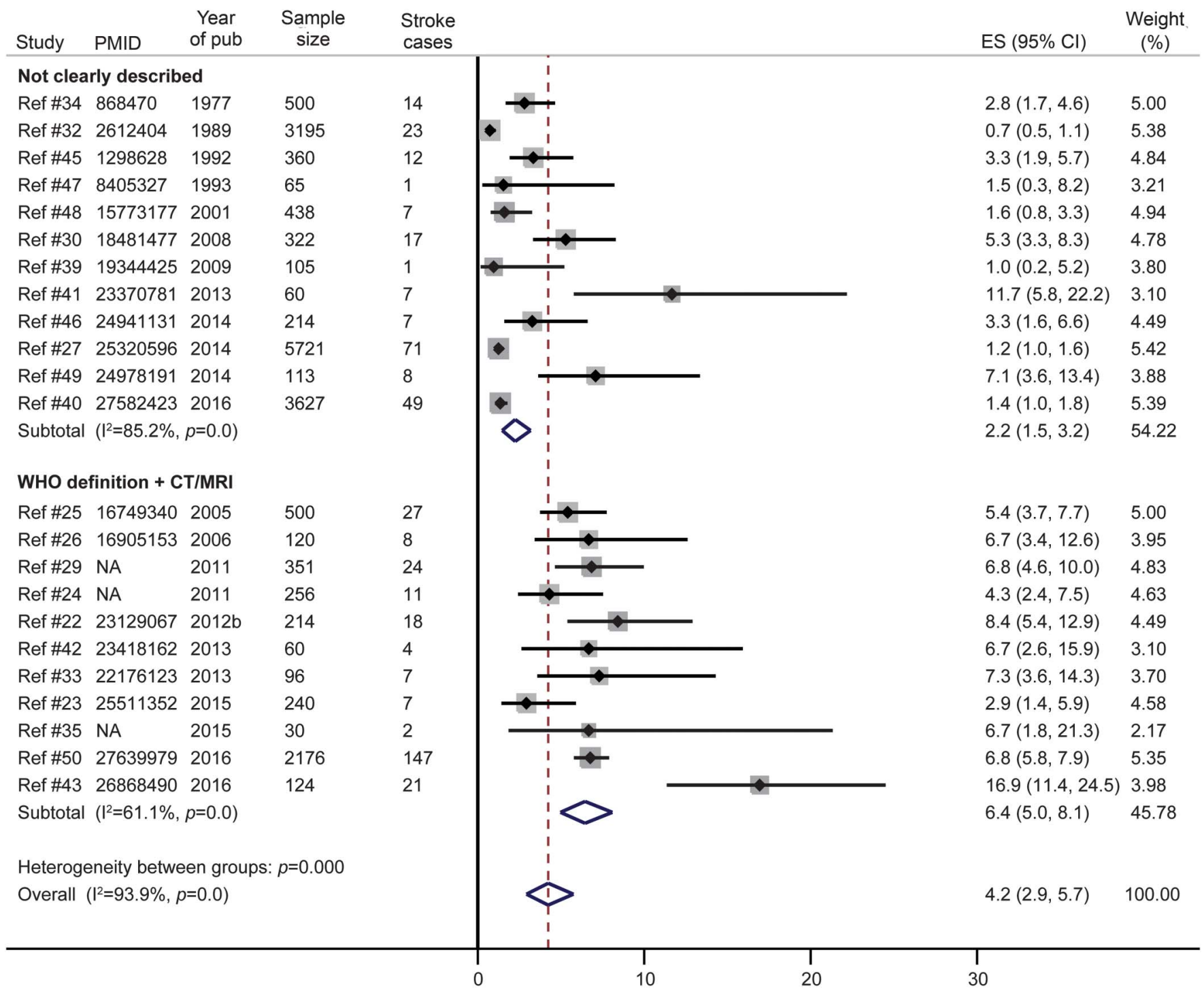

$\mathrm{Cl}=$ confidence interval; $\mathrm{ES}=$ effect size; $\mathrm{NA}=$ not available (article not indexed in PubMed/no accession number available). 
a brain CT was performed in all patients with stroke, revealing an ischemic lesion in $94.4 \%$ (17/18) of cases. $^{22}$ In the other 3 studies, brain CT/MRI was performed only for a few patients with clinical features of stroke $(4 / 5,3 / 11$, and $7 / 25$ patients, respectively) $)^{23-25}$; the stroke was ischemic in all cases with brain imaging (4/4 and 3/3) in 2 studies, ${ }^{23,24}$ and in $71.4 \%(5 / 7)$ of cases in the third. ${ }^{25}$

The 5 studies reporting data on stroke recurrence are listed in table e-2. ${ }^{22,24,26-28}$ The prevalence of recurrent stroke varied from $18.2 \%(2 / 11)$ to $77.8 \%(14 / 18)$. In one study, ${ }^{28}$ the incidence of stroke recurrence was $28 / 100$ person-years in 18 patients not taking hydroxyurea and 7/100 person-years in 13 patients on hydroxyurea. Children who did not receive hydroxyurea were more likely to drop out of school and to have moderate to severe motor disabilities requiring caregiver assistance for daily living. There was no difference in the rate of children developing epilepsy during the 30-month follow-up (23.1\% in children on hydroxyurea vs $16.7 \%$ in children not taking hydroxyurea).
Two other studies reported on long-term sequelae of stroke in children with SCD. ${ }^{25,29}$ Speech impairment (aphasia or dysphasia) was found in 12\% (3/25) and $73.9 \%(17 / 23)$, intellectual disability in $8 \%$ $(2 / 25)$ and $52.2 \%(12 / 23)$, motor disability (hemiparesis or quadriparesis) in 76\% (19/25) and 83.3\% $(20 / 23)$, and seizures/epilepsy in $24 \%(6 / 25)$ and $30.4 \%(7 / 23)$ of children who survived after a stroke.

Conditional or abnormal cerebral blood flow. Cerebral blood flow (CBF) in people with SCD was investigated in 7 studies using transcranial Doppler to obtain the time-averaged mean of the maximum velocities (TAMM). The overall prevalence of conditional CBF (TAMM between 170 and $200 \mathrm{~cm} / \mathrm{s}$ ) was $10.6 \%$ in a pooled sample of 1,573 participants from 6 studies (figure 3). The overall prevalence of abnormal CBF (TAMM $>200 \mathrm{~cm} / \mathrm{s}$ ) was $6.1 \%$ in a pooled sample of 1,500 participants from 7 studies (figure 3). The Egger test for small-study effect was not significant in either subgroup (bias statistic = 0.87 and 0.45 , respectively; $p=0.40$ and 0.50 , respectively).

Figure 3 Meta-analysis of the prevalence of conditional/abnormal cerebral blood flow (CBF) in sickle cell disease

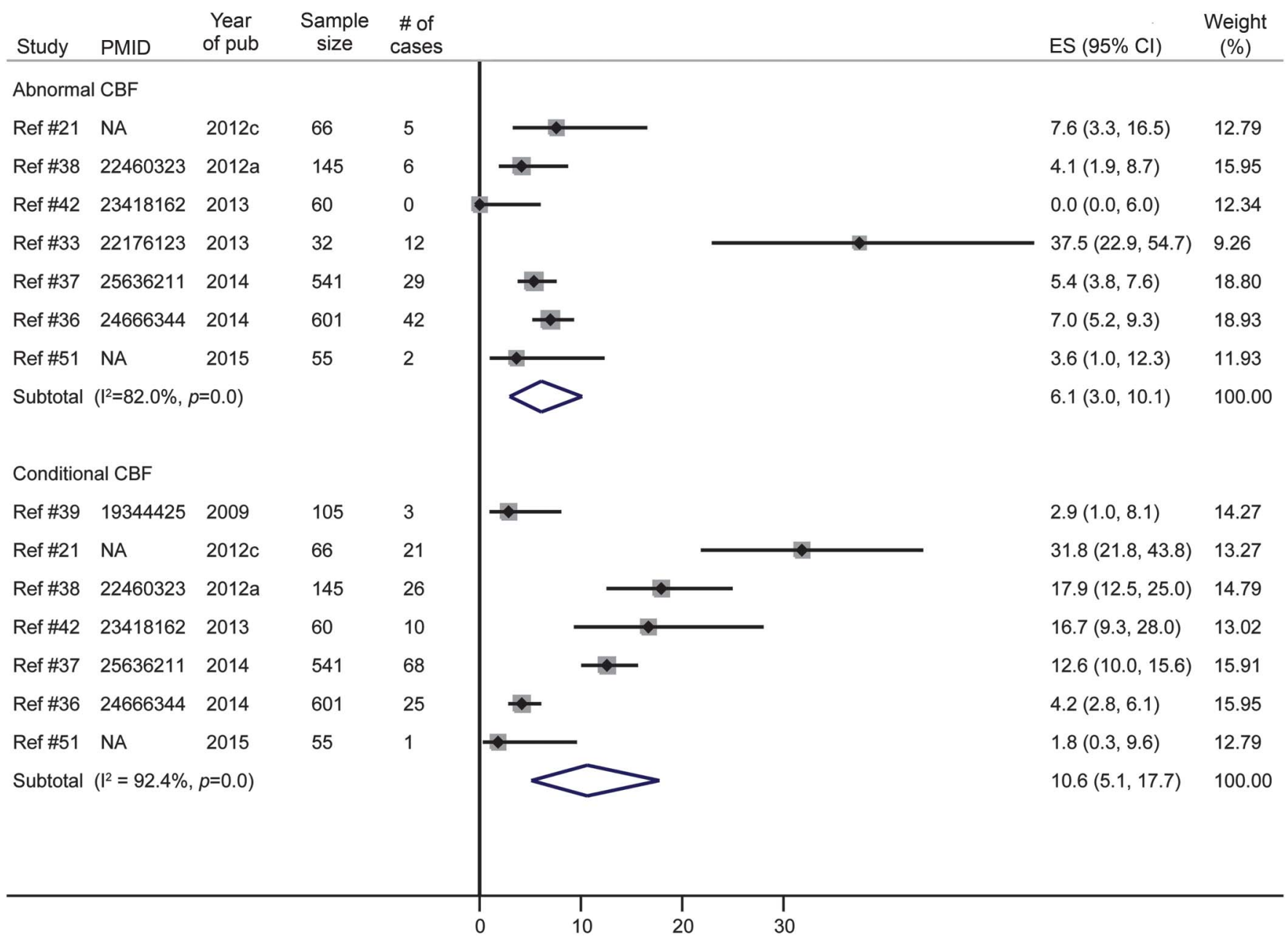

$\mathrm{Cl}=$ confidence interval; $\mathrm{ES}$ = effect size; $\mathrm{NA}=$ not available (article not indexed in PubMed/no accession number available). 
Seizures. The prevalence of seizures was reported in 9 studies, with 4 making a clear description of the etiology (febrile convulsions, provoked seizures, single symptomatic seizures, epilepsy) $)^{22,30-32}$ and only 2 using EEG. ${ }^{22,31}$ The overall prevalence of seizures in SCD was $4.4 \%$ in a pooled sample of 5,383 patients (figure 4). This prevalence was higher in studies with smaller sample size and there was significant intergroup heterogeneity (heterogeneity statistic $=4.2$, $p=0.04)$. The Egger test for small study effect was not significant (bias statistic $=1.02, p=0.08$ ). The prevalence of seizures in SCD was lower in studies published before 2008 (figure e-4). Specifically, in a pooled sample of 3,505 patients from 3 studies, the prevalence of febrile convulsions was $3.0 \%$ (figure e-5) and that of epilepsy was $2.8 \%$ (figure e-6).

Other neurologic complications. The prevalence of recurrent headache in SCD was $18.9 \%$ in a pooled sample of 673 patients from 4 studies (figure 5). One study in Cameroon evaluated the cognitive function (executive function, attention, memory, and motor skills) of 96 patients with SCD aged 6-24 years (mean 13.5, SD 4.9). Mild or severe cognitive deficits were reported in 15 (15.6\%) and 21 (21.9\%) patients, respectively. ${ }^{33}$ In another study in the Democratic Republic of Congo, 17.5\% (7/40) of patients with SCD were found to have cognitive and motor deficits. ${ }^{34}$

A Nigerian study found a prevalence of localized sensory neuropathy of $2.1 \%$ (2/96), 16.8\% (38/226), and $4.1 \%(12 / 291)$ among children (4-14 years), adolescents (15-19 years), and adults ( $\geq 20$ years) with SCD, respectively, giving an overall prevalence of $8.5 \%(52 / 613) .{ }^{30}$ One study reported the prevalence of silent brain infarcts, which was $16.7 \%(5 / 30)$ in patients with SCD younger than 18 years. ${ }^{35}$

DISCUSSION This systematic review and metaanalysis shows that stroke, conditional and abnormal $\mathrm{CBF}$, seizures, and headache are the neurologic complications of SCD most frequently reported, with an overall prevalence of $4.2 \%, 10.6 \%, 6.1 \%, 4.4 \%$,

Figure 4 Meta-analysis of the prevalence of seizure in sickle cell disease according to the study size

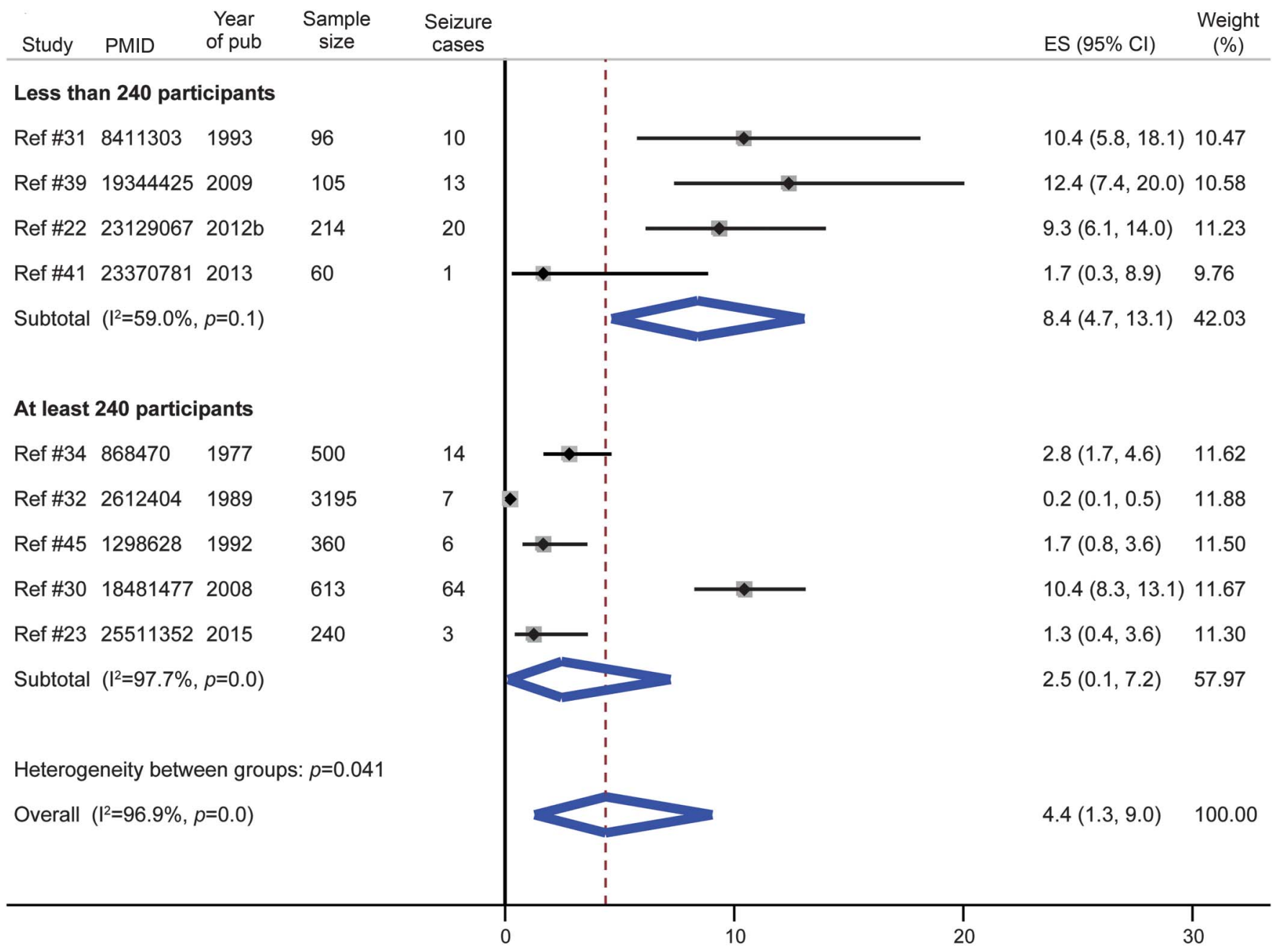

$\mathrm{Cl}=$ confidence interval; $\mathrm{ES}=$ effect size. 
Figure 5 Meta-analysis of the prevalence of headache in patients with sickle cell disease

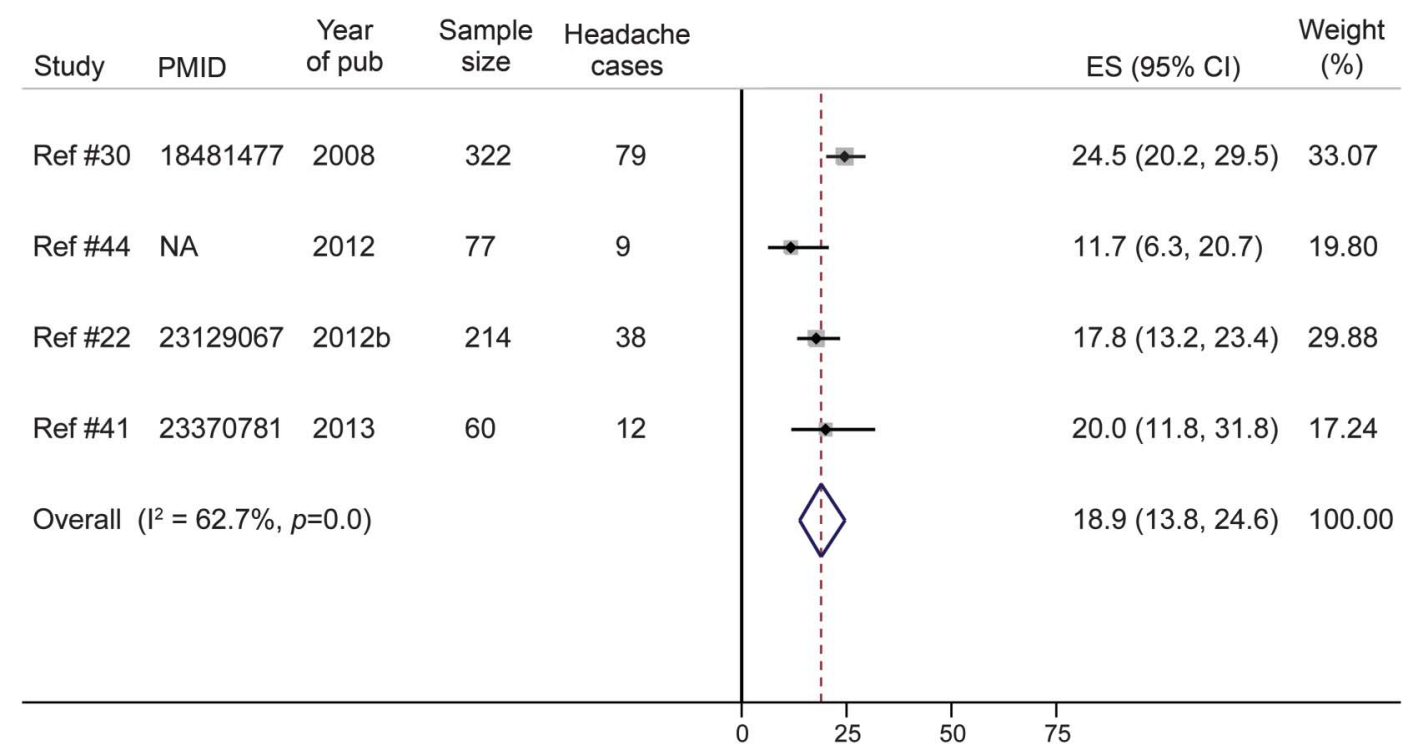

$\mathrm{Cl}=$ confidence interval; $\mathrm{ES}=$ effect size; $\mathrm{NA}=$ not available (article not indexed in PubMed/no accession number available).

and $18.9 \%$, respectively. It also highlights the fact that some complications like silent brain infarcts, peripheral neuropathies, neurocognitive deficits, and moyamoya disease have been studied rarely or not at all in the African setting. Overall, the epidemiology of neurologic complications in SCD seems to be different in patients residing in Africa when compared to those not residing in Africa.

The prevalence of stroke in SCD is about 3 times higher in studies that used more reliable case definitions and diagnostic tools as compared to those with unclear case definitions (6.4\% vs $2.2 \%$ ). Therefore, the prevalence of stroke in African patients with SCD is probably underestimated, especially when considering the higher prevalence reported in other settings $(8 \%-11 \%){ }^{5,52}$ Consistent with data from other populations, ${ }^{5}$ we found that ischemic lesions were the most frequent type of stroke. Despite being of limited precision (retrospective data collection in small samples), available data show that stroke recurrence is observed in $18 \%-78 \%$ of patients with SCD, with higher recurrence rates recorded in those not taking hydroxyurea, ${ }^{28}$ thus highlighting the potential benefit of this drug for secondary stroke prevention in low to middle income countries where the current standard treatment-chronic transfusion therapy $(\mathrm{CTT})^{53}$ — is most often not affordable. Hydroxyurea seems to bear even more hope for patients with SCD in Africa when considering the results of the TCD With Transfusions Changing to Hydroxyurea (TWiTCH) trial demonstrating the noninferiority of hydroxyurea over chronic blood transfusion for primary stroke prevention in SCD after at least 1 year of CTT. ${ }^{54}$ Increasing the accessibility to early transcranial Doppler (TCD) screening and early initiation of hydroxyurea before the first overt stroke could be far more promising options to reduce the burden of stroke in SCD. However, it is not yet known if the beneficial effects of hydroxyurea would be identical if started immediately after the detection of abnormal TCD velocities in CTT-naive patients. ${ }^{55}$ Hopefully the ongoing randomized clinical trial in Nigeria (NCT02560935) will help to fill this knowledge gap.

The pooled prevalence of conditional and abnormal CBF in this study $(10.6 \%$ and $6.1 \%$, respectively) are far lower than those found in populations outside Africa. For instance, the Centre Hospitalier Intercommunal de Creteil newborn cohort study in France found a prevalence of abnormal CBF of nearly $30 \% .{ }^{56}$ Moreover, only one small-sized study in this review investigated the prevalence of silent brain infarcts, reporting a prevalence of $16.7 \%$, which is lower than the prevalence of $39 \%$ by 18 years found in non-African populations. ${ }^{57}$ These lower rates of stroke, silent brain infarcts, and abnormal CBF in African patients with SCD might be explained by the limited access to screening and diagnostic tools (TCD, CT, MRI) as well as the poorer documentation and follow-up due to limited availability of trained health personnel who would be able to identify, report, and manage cases adequately.

Seizures represent another common neurologic complication of SCD. Recurrent seizures (epilepsy) are 2-3 times more frequent in individuals with SCD than in the general population, and are associated with premature death. ${ }^{4,58}$ In the Jamaica cohort study of SCD, approximately $7 \%$ of individuals had 
experienced at least 1 seizure. ${ }^{58}$ The frequency of seizures in this meta-analysis (4.4\%) is lower and might be explained by the predominance of older studies conducted before the 21st century. These studies provide nearly $80 \%$ of the pooled sample used in the meta-analysis of seizures data. It is likely that the data reported in older studies were of poor quality due to low public awareness, limited availability of trained health personnel, and poor access to adequate diagnostic resources. Indeed, the overall prevalence of seizures in studies conducted after $2008(6.3 \%)$ is closer to that obtained in the Jamaica cohort study. ${ }^{58}$

This review reveals that recurrent headache is a common $(18.9 \%)$ problem in patients with SCD in Africa, though less frequent than reported in high-income settings. For instance, in a large retrospective cross-sectional study in the United States $(\mathrm{n}=872)$, recurrent headache and migraine were found in $36.1 \%$ and $15.1 \%$ of children with SCD, respectively. ${ }^{59}$ The pathogenesis of headache in SCD remains unclear, but factors like anemia or stress have been suggested as possible mechanisms. Some studies have shown an association between headache and low hemoglobin level, and others have demonstrated an improvement of headache following blood transfusion. ${ }^{5}$

Of the 2 studies assessing neurocognitive deficits in SCD in Africa, one used a well-structured neuropsychological test battery and found a higher frequency of cognitive deficits (37.5\%) than usually reported in western countries. ${ }^{33}$ This study conducted in Cameroon also reported a decline in attention and executive functions in late childhood, thus highlighting the need to integrate a long-term neuropsychological assessment as part of the routine care of children with SCD and to discuss the potential benefits of specific cognitive training programs for selected groups. However, further studies are needed to provide a more detailed description of the neurocognitive functions that are affected in patients with SCD in Africa, so as to inform the design of rehabilitation programs.

The interpretation of our results should take into account a few limitations that could alter the accuracy or the precision of our estimations: (1) the substantial heterogeneity between studies in most of the metaanalyses performed, (2) the retrospective data collection in most of the studies included, and (3) the lack of clear case definitions or reliable diagnostic tools in some studies. Nevertheless, the stringent criteria applied during the selection of studies and the rigorous methodology used for data analysis helped to mitigate the effects of these limitations.

The burden of neurologic complications of SCD such as stroke, seizures, neurocognitive deficits, and headache is important in Africa and most likely underestimated. Indeed, the prevalence of these complications are lower than in non-African populations, contrasting with a higher vulnerability of patients with SCD in Africa due to limited access to adequate preventive and therapeutic interventions. The difference is probably due to the inadequacy of the diagnostic methods used in many African studies. Consequently, there is a need for larger prospective studies investigating all neurologic complications of SCD using standard up-to-date screening methods in order to increase the detection rate. Finally, efforts are needed to increase public awareness of neurologic complications of SCD; accessibility to adequate diagnostic tools (neuroimaging, TCD, EEG, neuropsychological evaluation) and preventive and therapeutic interventions; as well as availability of trained health care providers.

\section{AUTHOR CONTRIBUTIONS}

J.J.N., M.K.M., N.N., and J.K.-T. conceived the study and designed the protocol. N.N. performed the literature search. J.J.N. and J.K.-T. selected the studies. J.J.N., M.K.M., N.N., and J.K.-T. extracted the relevant information. J.K.-T. and J.J.N. synthesized the data. J.J.N. and J.K.-T. wrote the first draft of the paper. J.J.N., M.K.M., N.N., and J.K.-T. critically revised successive drafts of the paper and approved the final version. J.J.N. is the guarantor of the review.

\section{STUDY FUNDING}

No targeted funding reported.

\section{DISCLOSURE}

The authors report no disclosures relevant to the manuscript. Go to Neurology.org for full disclosures.

Received January 5, 2017. Accepted in final form June 22, 2017.

\section{REFERENCES}

1. Modell B, Darlison M. Global epidemiology of haemoglobin disorders and derived service indicators. Bull World Health Organ 2008;86:480-487.

2. Aygun B, Odame I. A global perspective on sickle cell disease. Pediatr Blood Cancer 2012;59:386-390.

3. Venkataraman A, Adams RJ. Neurologic complications of sickle cell disease. Handb Clin Neurol 2014;120:10151025 .

4. DeBaun MR, Kirkham FJ. Central nervous system complications and management in sickle cell disease. Blood 2016;127:829-838.

5. Al-Jafar HA, Alroughani R, Abdullah TA, Al-Qallaf F. Neurological complications of sickle cell disease. Int J Clin Exp Neurol 2016;4:9-18.

6. Mulumba LL, Wilson L. Sickle cell disease among children in Africa: an integrative literature review and global recommendations. Int J Afr Nurs Sci 2015;3:56-64.

7. Mengnjo MK, Kamtchum-Tatuene J, Nicastro $\mathrm{N}$, Noubiap JJ. Neurological complications of sickle cell disease in Africa: protocol for a systematic review. BMJ Open 2016;6:e012981.

8. McHugh ML. Interrater reliability: the kappa statistic. Biochem Med 2012;22:276-282.

9. Cohen J. A coefficient of agreement for nominal scales. Educ Psychol Meas 1960;20:37-46. 
10. Sim J, Wright CC. The kappa statistic in reliability studies: use, interpretation, and sample size requirements. Phys Ther 2005;85:257-268.

11. Hoy D, Brooks P, Woolf A, et al. Assessing risk of bias in prevalence studies: modification of an existing tool and evidence of interrater agreement. J Clin Epidemiol 2012; 65:934-939.

12. Cohen J. Weighted kappa: nominal scale agreement with provision for scaled disagreement or partial credit. Psychol Bull 1968;70:213-220.

13. Viera AJ, Garrett JM. Understanding interobserver agreement: the kappa statistic. Fam Med 2005;37:360-363.

14. Nyaga VN, Arbyn M, Aerts M. Metaprop: a Stata command to perform meta-analysis of binomial data. Arch Public Health 2014;72:39.

15. Huedo-Medina TB, Sanchez-Meca J, Marin-Martinez F, Botella J. Assessing heterogeneity in meta-analysis: Q statistic or I2 index? Psychol Methods 2006;11:193-206.

16. Newcombe RG. Two-sided confidence intervals for the single proportion: comparison of seven methods. Stat Med 1998;17:857-872.

17. DerSimonian R, Laird N. Meta-analysis in clinical trials. Control Clin Trials 1986;7:177-188.

18. Barendregt JJ, Doi SA, Lee YY, Norman RE, Vos T. Meta-analysis of prevalence. J Epidemiol Community Health 2013;67:974-978.

19. Freeman MF, Tukey JW. Transformations related to the angular and the square root. Ann Math Statist 1950;21: 607-611.

20. Sterne JA, Egger M, Moher D. Addressing reporting biases. In: Higgins JP, Green S, eds. Cochrane Handbook for Systematic Reviews of Interventions. Chichester: Wiley; 2008:297-334.

21. Lagunju I, Sodeinde O. Prospective measurement of stroke incidence in childhood sickle cell disease. Arch Dis Child 2012;97:A45.

22. Lagunju IA, Brown BJ. Adverse neurological outcomes in Nigerian children with sickle cell disease. Int J Hematol 2012;96:710-718.

23. Adegoke SA, Adeodu OO, Adekile AD. Sickle cell disease clinical phenotypes in children from South-Western Nigeria. Niger J Clin Pract 2015;18:95-101.

24. George IO, Frank-Briggs AI. Stroke in Nigerian children with sickle cell anaemia. J Public Health Epidemiol 2011; 3:407-409.

25. Fatunde OJ, Adamson FG, Ogunseyinde O, Sodeinde O, Familusi JB. Stroke in Nigerian children with sickle cell disease. Afr J Med Med Sci 2005;34:157-160.

26. Njamnshi AK, Mbong EN, Wonkam A, et al. The epidemiology of stroke in sickle cell patients in Yaounde, Cameroon. J Neurol Sci 2006;250:79-84.

27. Jude MA, Aliyu GN, Nalado AM, et al. Stroke prevalence amongst sickle cell disease patients in Nigeria: a multicentre study. Afr Health Sci 2014;14:446-452.

28. Lagunju IA, Brown BJ, Sodeinde OO. Stroke recurrence in Nigerian children with sickle cell disease treated with hydroxyurea. Niger Postgrad Med J 2013;20:181-187.

29. Lagunju IA, Brown BJ, Famosaya AA. Childhood stroke in sickle cell disease in Nigeria. J Pediatr Neurol 2011;9: 49-53.

30. Kehinde MO, Temiye EO, Danesi MA. Neurological complications of sickle cell anemia in Nigerian Africans: a case-control study. J Natl Med Assoc 2008;100:394399.
31. Adamolekun B, Durosinmi MA, Olowu W, Adediran I. The prevalence and classification of epileptic seizures in Nigerians with sickle-cell anaemia. J Trop Med Hyg 1993; 96:288-290.

32. Izuora GI, Kaine WN, Emodi I. Neurological disorders in Nigerian children with homozygous sickle cell anaemia. East Afr Med J 1989;66:653-657.

33. Ruffieux N, Njamnshi AK, Wonkam A, et al. Association between biological markers of sickle cell disease and cognitive functioning amongst Cameroonian children. Child Neuropsychol 2013;19:143-160.

34. Djunga S, Clarysse J. Neurological complications in sickle cell disease (author's transl) [in French]. Acta Neurol Belg 1977;77:105-114.

35. Tantawy AAG, El Rakawy MH, Mohamed SA, Dewedar AAZ, Arziz AANA, Ghani AA. MRI brain in young Egyptian sickle cell disease patients: relation to cerebral blood flow and neuropsychometric evaluation. Haematologica 2015;100:783.

36. Cox SE, Makani J, Soka D, et al. Haptoglobin, alphathalassemia and glucose-6-phosphate dehydrogenase polymorphisms and risk of abnormal transcranial Doppler among patients with sickle cell anaemia in Tanzania. $\mathrm{Br}$ J Haematol 2014;165:699-706.

37. Dorie A, Guindo A, Saro YS, et al. Screening of cerebral vasculopathy in sickle cell anemia children using transcranial Doppler [in French]. Arch Pediatr 2015; 22:260-266.

38. Lagunju I, Sodeinde O, Telfer P. Prevalence of transcranial Doppler abnormalities in Nigerian children with sickle cell disease. Am J Hematol 2012;87:544-547.

39. Makani J, Kirkham FJ, Komba A, et al. Risk factors for high cerebral blood flow velocity and death in Kenyan children with sickle cell anaemia: role of haemoglobin oxygen saturation and febrile illness. $\mathrm{Br} \mathrm{J}$ Haematol 2009;145:529-532.

40. Ranque B, Menet A, Boutouyrie P, et al. Arterial stiffness impairment in sickle cell disease associated with chronic vascular complications: the Multinational African CADRE study. Circulation 2016;134:923-933.

41. Tabari AM, Ismail A. Doppler ultrasound velocimetry of middle cerebral arteries of patients with sickle cell disease at Aminu Kano Teaching Hospital: a preliminary report. Ultrasound Q 2013;29:61-65.

42. Tantawy AA, Andrawes NG, Adly AA, El Kady BA, Shalash AS. Retinal changes in children and adolescents with sickle cell disease attending a paediatric hospital in Cairo, Egypt: risk factors and relation to ophthalmic and cerebral blood flow. Trans R Soc Trop Med Hyg 2013; 107:205-211.

43. Saidi H, Smart LR, Kamugisha E, et al. Complications of sickle cell anaemia in children in Northwestern Tanzania. Hematology 2016;21:248-256.

44. Wahab K, Olanrewaju T, Aderibigbe A. One-year prevalence of recurrent headaches among adult Nigerians with sickle cell disease. Neurology 2012;78(suppl 1):P04.236.

45. Amayo EO, Owade JN, Aluoch JR, Njeru EK. Neurological complications of sickle cell anaemia at $\mathrm{KNH}$ : a five year retrospective study. East Afr Med J 1992; 69:660-662.

46. Akingbola TS, Tayo BO, Salako B, et al. Comparison of patients from Nigeria and the USA highlights modifiable risk factors for sickle cell anemia complications. Hemoglobin 2014;38:236-243. 
47. de Montalembert M, Guilloud-Bataille M, Feingold J, Girot R. Epidemiological and clinical study of sickle cell disease in France, French Guiana and Algeria. Eur J Haematol 1993;51:136-140.

48. Diagne I, Diagne-Gueye NR, Fall L, et al. Acute encephalic manifestations in Senegalese children with sickle cell disease [in French]. Dakar Med 2001;46:116-120.

49. Rumaney MB, Ngo Bitoungui VJ, Vorster AA, et al. The co-inheritance of alpha-thalassemia and sickle cell anemia is associated with better hematological indices and lower consultations rate in Cameroonian patients and could improve their survival. PLoS One 2014;9:e100516.

50. Munube D, Katabira E, Ndeezi G, et al. Prevalence of stroke in children admitted with sickle cell anaemia to Mulago Hospital. BMC Neurol 2016;16:175.

51. Elbeshlawy A, El Tagui M, Raouf E, et al. Transcranial Doppler imaging in the management of pediatric sickle cell disease patients: impact of hydroxyurea. Haematologica 2013;98(suppl 1):718

52. Steen RG, Emudianughe T, Hankins GM, et al. Brain imaging findings in pediatric patients with sickle cell disease. Radiology 2003;228:216-225.

53. Ware RE, Helms RW, Investigators SW. Stroke With Transfusions Changing to Hydroxyurea (SWiTCH). Blood 2012; 119:3925-3932.
54. Ware RE, Davis BR, Schultz WH, et al. Hydroxycarbamide versus chronic transfusion for maintenance of transcranial Doppler flow velocities in children with sickle cell anaemia: TCD With Transfusions Changing to Hydroxyurea (TWiTCH): a multicentre, open-label, phase 3, noninferiority trial. Lancet 2016;387:661-670.

55. DeBaun MR, Kirkham FJ. New option for primary stroke prevention in sickle cell anaemia. Lancet 2016;387:626627.

56. Bernaudin F, Verlhac S, Arnaud C, et al. Long-term treatment follow-up of children with sickle cell disease monitored with abnormal transcranial Doppler velocities. Blood 2016;127:1814-1822.

57. Bernaudin F, Verlhac S, Arnaud C, et al. Chronic and acute anemia and extracranial internal carotid stenosis are risk factors for silent cerebral infarcts in sickle cell anemia. Blood 2015;125:1653-1661.

58. Ali SB, Reid M, Fraser R, MooSang M, Ali A. Seizures in the Jamaica cohort study of sickle cell disease. Br J Haematol 2010;151:265-272.

59. Dowling MM, Noetzel MJ, Rodeghier MJ, et al. Headache and migraine in children with sickle cell disease are associated with lower hemoglobin and higher pain event rates but not silent cerebral infarction. J Pediatr 2014;164: 1175-1180. 


\section{Neurology}

\section{Neurologic complications of sickle cell disease in Africa: A systematic review and meta-analysis}

Jean Jacques Noubiap, Michel K. Mengnjo, Nicolas Nicastro, et al.

Neurology 2017;89;1516-1524 Published Online before print September 1, 2017

DOI 10.1212/WNL.0000000000004537

This information is current as of September 1, 2017

Neurology ${ }^{\circledR}$ is the official journal of the American Academy of Neurology. Published continuously since 1951, it is now a weekly with 48 issues per year. Copyright Copyright ( 2017 The Author(s). Published by Wolters Kluwer Health, Inc. on behalf of the American Academy of Neurology. All rights reserved. Print ISSN: 0028-3878. Online ISSN: 1526-632X.

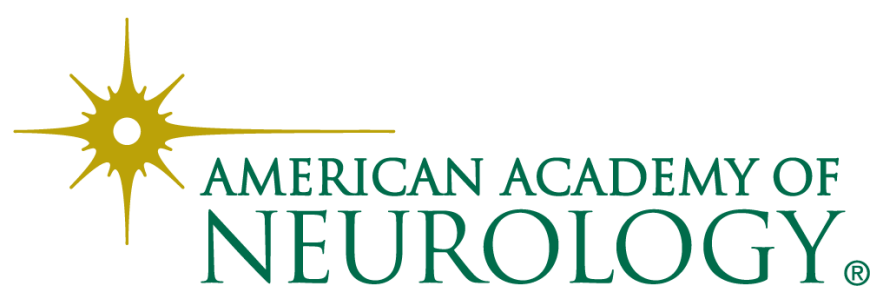




\section{Updated Information \& Services}

\section{Supplementary Material}

\section{References}

Citations

Subspecialty Collections

\section{Permissions \& Licensing}

Reprints including high resolution figures, can be found at: http://n.neurology.org/content/89/14/1516.full

Supplementary material can be found at: http://n.neurology.org/content/suppl/2017/09/01/WNL.0000000000004 537.DC1

http://n.neurology.org/content/suppl/2017/09/01/WNL.0000000000004 537.DC2

This article cites 58 articles, 10 of which you can access for free at: http://n.neurology.org/content/89/14/1516.full\#ref-list-1

This article has been cited by 2 HighWire-hosted articles: http://n.neurology.org/content/89/14/1516.full\#\#otherarticles

This article, along with others on similar topics, appears in the following collection(s):

\section{All global neurology}

http://n.neurology.org/cgi/collection/all_global_neurology

\section{Burden of disease}

http://n.neurology.org/cgi/collection/burden_of_disease

Underserved populations

http://n.neurology.org/cgi/collection/underserved_populations

Information about reproducing this article in parts (figures,tables) or in its entirety can be found online at:

http://www.neurology.org/about/about_the_journal\#permissions

Information about ordering reprints can be found online:

http://n.neurology.org/subscribers/advertise

Neurology ${ }^{\circledR}$ is the official journal of the American Academy of Neurology. Published continuously since 1951, it is now a weekly with 48 issues per year. Copyright Copyright ( 2017 The Author(s). Published by Wolters Kluwer Health, Inc. on behalf of the American Academy of Neurology. All rights reserved. Print ISSN: 0028-3878. Online ISSN: 1526-632X.

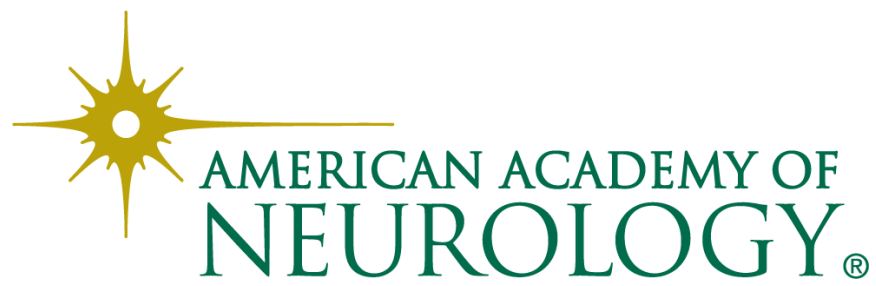

